\title{
Elwood Murray's Laboratory in Interpersonal Communication
}

\author{
Judith Brownell \\ State University of New York at Binghamton
}

\section{INTRODUCTION}

Of the many offerings that Elwood Murray introduced while chairman of the Department of Speech Communication at the University of Denver, ${ }^{1}$ the Laboratory in Interpersonal Communication stands out as significant to the field of speech on two accounts. First, it was one of the earliest offerings to focus on the practical application of general semantic principles. Second, the classroom methods Murray introduced to facilitate the teaching of Korzybski's formulations were at the time quite untraditional. Interpersonal communication classes today, however, appear to share many characteristics with Murray's original laboratory.

The purpose of this paper, then, is to describe the functioning of the Interpersonal Communication laboratory, illustrating Murray's use of social science methods to assist students in internalizing the principles of general semantics. ${ }^{2}$

\section{Overview of the Laboratory}

The central theme of the laboratory has been described by Murray as "knowing about our knowing"-a very difficult and complex task. ${ }^{3}$ The laboratory strove not only to improve the student's communication, but also his ability to communicate about his communication. The principles of general semantics served as a metalanguage as participants identified and discussed their own communicative acts. The functioning of the laboratory, as it assisted students in the improvement of their speech behaviors, could be viewed on three different levels - the intrapersonal, the interpersonal, and the communication process of the laboratory itself. ${ }^{4}$

First, self awareness - an understanding of one's own intrapersonal communication and how one talks silently to oneself-was essential. Interpersonal communication, Murray frequently explained, can "scarcely be better than the subvocal and nonverbal talking to the self which arises from the unconscious." Murray also described his model of interpersonal communication, which "derives from the semantic transaction as person A relates to person $B$ in an interaction with an environment." Again, Murray emphasized the study of both the individual and his interpersonal context in their entirety. Within the laboratory, this model incorporated methodology from the various areas of group dynamics, feedback theory from cybernetics and general systems, applied epistemology from general semantics, and the humanistic psychologies. ${ }^{7}$ 
The carefully designed structure of the laboratory greatly contributed to its effectiveness. The format and methodologies were developed in an effort to deal with the whole person in his total environment. Murray's earlier work in speech personality became incorporated into his view of interpersonal communication. As he wrote in 1948:

... the personality is both the cause and the result of communication in interpersonal relations. ... Better communication seems far more likely when the teacher of speech has evolved and mastered methodologies to teach his subject in its whole setting. This means that he will view speech as a medium of interpersonal relations and personality development which comes from orientation to a world of process and change. ${ }^{8}$

\section{Operation of the Laboratory}

The laboratory, as it was conceived and conducted by Murray for over twenty years at the University of Denver, was itself an excellent example of integration-lecture, methods, student involvement all contributed to the learning process. The following is a description of the format and operations of the laboratory as experienced by the hundreds of students who participated in Murray's elaborate seminar.

The laboratory usually met during the regular term for three hours one evening a week-from 7:00 p.m. until 10:00 p.m. For students who had been elected to the "Steering Committee," however, the session began at 6:30 p.m. when the group met with their instructor to discuss class progress, make any necessary changes in the functioning of the laboratory, and finalize plans for that evening's session. Each member of the committee had a specific role to fulfill which contributed to the achievement of the session's objectives.

Several members of the committee were represented on each of the three task groups into which the class was divided at the first session. Others were elected to positions such as "feedback chairman," "reporter," "librarian," or to any one of a number of other assignments. The roles of each of these participants facilitated the laboratory process by encouraging the group to look closely at its own communicative behavior. Murray explained:

A program chairperson is constantly studying the agenda...There is a group chairperson who makes "assignments" to the small groups, attempts to keep the groups balanced...A social chairperson is especially concerned with morale of the laboratory as a whole in making suggestions which prevent "slumps" in productivity...9

Members of the laboratory, then, were largely responsible for its operation and for insuring maximum learning and student involvement. One of the most important aspects of the laboratory process was the constant feedback generated on as many levels as possible within the group. In addition to 
verbal feedback from various group members, students were also requested to answer several questions in writing at the end of each session concerning aspects of the laboratory process. Included, too, were questions dealing with the student's satisfaction with the evening's work, and his recommendations for changes or modifications within the laboratory structure. These sheets were tabulated by the "feedback chairman" and distributed anonymously at the beginning of each class period, along with several other handouts.

On another level, each of the three laboratory groups had student "observers" who carefully noted the communication behavior of individuals and the group process as it unfolded. Later, they were asked to report their observations to the class. In addition, distinguished guests from other departments or from the community were invited to attend and observe the laboratory session. These individuals added insights from their disciplines or occupations. ${ }^{10}$ The highly structured feedback mechanism was a significant feature of the laboratory design.

The laboratory began with a brief report from the Steering Committee, and proceeded immediately to a class lecture on some "basic epistemic unit." Murray outlined the following units around which the laboratory content was organized:

Series I: The Semantics of Personal Adjustment

1. Communication: Relating, Influencing, Interacting.

2. Evaluating: The search for Probability-Predictability in the Fact-Structures.

3. Knowing as Abstracting. Delay of Reaction. From Sign to Signal to Symbol

4. Language-Fact Structures. Maps and Territories. Isomorphism. ${ }^{11}$

5. Circularity in the Ordering of Abstractings. Non-Identification. Non-Allness.

6. The Relational vs. The Elementalistic. Extensional-Intensional Orientation.

7. Dealing with Disorienting Verbalism: The Extensional Devices Defeating the Two-Values and Double Binds. Integration of Neural Levels.

8. Inner Silences and Calm for Alertness. Integration of Neural Levels, continued.

9. Perception of Order, Function, Structure, Transformations.

10. Spontaneity vs. Impulsiveness. Self-Reflexiveness into Creativity; Self-Reflexiveness into Conflict.

Series II. Expanding Awareness

11. The Nervous System (Organization) of your Enterprise.

12. Multi-Ordinality in the Social Networks. Of Abstracting; Of Statements, Of Reactions

13. For a Relational Perception of Self-Image and Self Identity.

14. Changing of Premise A to Premise B ('Persuasion'). Irreversibility and Non-Additivity. The Rogerian Feedback

15. Semantic Disorders in Our Knowledge About Each Others' Knowings About Our Knowings.

16. Over-Under Verbalization. Over-Under Definition.

17. Many Level vs. Dead Level Abstracting. Humanizing of Linguistics. 
18. Mathematics and the Nervous System.

19. The Power Factor (Field Forces) in Communication.

20. Status Communication and Productivity in Your Organization.

Series III. Mobilizing Knowledges for Communication

21. Deep Level Listening and Feedback Disorders. Group to Group Induction.

22. Communication in the Generational and Cultural Gaps.

23. Learning-Memory as Evident in Vocal-Bodily Delivery.

24. Purposes, Invention, and Organization as Emergents of Personality.

25. Non-Verbal, Non-Purposive, Para Communication and Ethos.

26. General Semantics in Policy-Making and Problem Solving.

27. Order Without Freedom. The Problem of Leadership.

28. Overcoming Semantic Disorders in Language Development from Childhood Learnings.

29. Cybernetics and Timebinding in Human Evolution (Negentropy).

30. The Humanities and Arts in Bringing Man Into a "Better" Isomorphism With His Universe. A Victory for the Semantic Hyphen. ${ }^{12}$

Although almost one third of each class session was devoted to lecture, Murray emphasized the fact that:

Lectures, textbook readings, and written assignments are not enough to make these insights operational and lasting. The deeper internalization is started immediately in each session as the students apply the lecture in the preparation and presentation of sociodrama, group evolved panels of pictures and diagrams, discussions and forums, guided observation and feedback activities. ${ }^{13}$

During the greatest portion of the class period, students were divided into three groups. Each group was responsible for preparing and presenting to the class a specific type of project which illustrated some application of the lecture material. One group was assigned to draw pictures, one to role play communication situations, and the third to present a panel or forum discussion.

The group concerned with the lowest level of abstraction-that closest to the factual level of experience-were the picture makers, who planned a series of drawings to illustrate concepts from the lecture material nonverbally. The role players would then dramatize a communication problem resulting from neglect of the general semantics principle discussed. The sociodrama group used such techniques as alter egos, hidden agendas, and soliloquys to illustrate their points effectively. Usually the role play was performed at least twice, the second time demonstrating a solution to the problem presented in the first scene. ${ }^{14}$ Lastly, there was a forum discussion group which operated at the highest level of abstraction. The forum group planned a panel or symposium which would involve the rest of the class in a discussion of various aspects and applications of the content of the evening's lecture. As Murray explained, "The idea is to stimulate thought and discussion, not necessarily to solve problems." 15 
Group members would therefore assume various roles in order to provoke more insightful dialogue and discussion.

Instructions to all groups were often deliberately imprecise, forcing members to come up with imaginative answers to the assigned questions. In describing the laboratory, Dr. Gail Myers gave an example of Murray asking a group on one occasion to "describe the color red." ${ }^{16}$ Another former student, Dr. Roy Wood, had the following insight to add:

The care and completeness with which he organized the Lab belied the image of the absent minded professor. The assignments were often confusing and incomplete but, I suspect, purposely so. ... I'll give you an example of why I think that. The...laboratory phase began when the groups were given written assignments. The assignments were vague, confusing, and apparently unrelated to the lectures. As a hot-shot senior, I decided to help Professor Murray improve his course. I told him about the problem in communication he had and offered to do an independent study to rewrite and clarify each assignment for each session. He smiled and said, "Roy, it took me years to get them that way!"17

Within each of the three groups, an observer carefully watched the communicative behavior among members as they discussed and planned their projects. Each observer also noted the reaction of class members to the group presentation, with particular regard to those aspects of communication covered in that evening's lecture. Later, as mentioned, each observer reported his perceptions to the class.

In most cases, there was also another observer present, who Murray called the "Barney Baruch." This was the "expert" or guest mentioned earlier, who played an important role in the laboratory session.

As you know, Barney Baruch observed the world from his park bench and with detached wisdom served as advisor and critic and commentator to world leaders. The lab's Barney Baruch spends his evening roaming around the class observing the process, and then at the close of the session gives a ... critique on the entire evening-including the lecture. ${ }^{18}$

Since there was frequent comment on the interpersonal behavior of members in the laboratory, the atmosphere and attitude created within the class became extremely important factors in insuring that such comments would be received and handled effectively. As Murray described a well-functioning laboratory:

Here the member is free to find ... the points in which his behavior is perceived as inappropriate. He is free to make a fool of himself without being made uncomfortable. Experience in the laboratory enables the members gradually to bring these behaviors into consciousness, and to experiment and practice in applications of semantic, psychological, and other methodology relevant to the communication process. ${ }^{19}$ 
Constructive criticism, of both the group presentations and the communicative behavior of individual members, was an essential part of the learning process. The timing of such feedback, however, was crucial-such comments must be appropriate. Murray noted with humor:

If speech criticism is emphasized too soon the non-speech majors will label the course as "just another speech course;" if not introduced soon enough the speech majors will say, "It is not speech!" Both reactions result from too narrow thinking and definition. ${ }^{20}$

\section{Evaluation of the Laboratory}

Certainly, not every student who has taken Murray's laboratory in Interpersonal Communication has found it exciting, and there are undoubtedly those who felt no practical benefit from their class participation. Measures taken thus far to determine the Laboratory's effectiveness, however, have uncovered generally positive results.

In a study of the effects of the laboratory experience on fifty-two teachers from the Jefferson County Schools in Colorado, for instance, Dr. Alvin Goldberg found that standardized test scores measured individuals to be significantly less dogmatic and opinionated after participating in Murray's interpersonal laboratory. ${ }^{21}$ This finding suggests that, at least for some laboratory participants, new patterns of thinking and evaluating had been established.

In 1973, two of Murray's former students, Dr. Gail Myers and his wife Michele Tolela, wrote a textbook in interpersonal communication based to a large extent on the content and methods of Murray's laboratory. The text, revised in 1976, was titled The Dynamics of Human Communication: A Laboratory Approach ${ }^{22}$ The success this publication has enjoyed ${ }^{23}$ would seem to indicate that educators throughout the country have found Murray's laboratory approach to be a viable and effective teaching design.

\section{CONCLUSION}

Several conclusions might be drawn concerning the present status of Murray's laboratory content and methods. Although the term "mental hygiene" is seldom used, present day interpersonal communication texts often advocate goals very similar to those presented in the laboratory sessions. Emphasis in many undergraduate interpersonal communication classes is placed on constructive behavior change, on the acquisition and internalization of new attitudes and skills. Activities are employed for the purpose of behavior change and personal growth. ${ }^{24}$

Group dynamics approaches in communication, particularly as they are used to teach interpersonal communication, have become an accepted if not important aspect of training in both the educational and industrial settings. Major businesses are 
becoming increasingly concerned with the interpersonal effectiveness of their managers (and other personnel), an area Murray recognized as important in the 1930's. ${ }^{25}$

From a review of recent interpersonal communication texts it also appears that general semantics-although not always referred to as such-continues to be a fundamental area within most college level courses. As Alton Barbour, one of Murray's former students and colleagues, noted, general semantics is often disguised but, upon further investigation, Korzybski's principles become readily apparent. ${ }^{26}$ Although the term itself may be avoided, the general semantics orientation appears to have remained an integral part of interpersonal communication instruction.

There is little doubt that Murray's efforts did contribute very directly to the development of procedures for teaching Korzybski's formulations. In 1977 Charlotte Read, then director of the Institute of General Semantics, commented on Murray's laboratory methods:

... he made valuable contributions to the teaching of general semantics by getting students to use it in action, in their behavior. ... He believed that consciousness of abstracting was basic, and he showed how it could be more effectively taught, and learned. ${ }^{27}$

As Donald Washburn stated, Murray was "a man with a vision who saw something of great value and who brought it into academia and gave it respectability ... a man who understood the value of the original thinking and who was able to develop it in an academic context." 28

Although many general semantics advocates have been accused of being closed- minded and parochial, Murray worked constantly to synthesize general semantics with other disciplines and to develop better ways to apply Korzybski's principles in the classroom. As Read again noted:

Dr. Murray had a rare ability to be open to many new and sound disciplines as they appeared, to appreciate their value and to incorporate them into and enrich his teaching approaches. This is what he also did with general semantics, and in the process he also enriched general semantics. ${ }^{29}$

In a recent article Murray summarized what he felt the contribution of general semantics could be, and what he believed to be the future challenge of man:

Man as the unique symbolizing organism will never stop searching for the greatest meanings of all, the meaning of man and the meaning of the universe. If these meanings are to be ever more penetratingly and comprehensively discovered, man must continue searching into his searchings, a matter which requires that he become more aware of his manner of searching. Nothing is more relevant to communication. ${ }^{30}$ 
Through the years El wood Murray's Laboratory in Interpersonal Communication, and the subsequent courses it inspired, have provided many scholars with the tools and motivation to pursue this search. 


\section{NOTES}

1. When Murray became chairman of the Department of Dramatic Arts and Speech in 1933, his influence was most vividly felt in the area of curriculum development. New offerings were added to the existing programs. While many of these were in speech science, all in some way developed Murray's holistic and personality approaches to speech behavior. "Speech Pathology," introduced in 1932, was one of the first speech science courses offered at a university in the western U.S.

2. For additional background information on Elwood Murray, see Judith Brownell, "Elwood Murray's Interdisciplinary Analogue Laboratory," Communication Education, Volume 28 (January, 1979), pp. 9-21.

3. Elwood Murray, "Teaching for an Optimum of Group Health: An Epistemic-Based Laboratory in Interpersonal Communication," Paper presented at a joint research conference with the American Society for Psychosomatic Dentistry and Medicine, Mt. Pocono, Pa., October 7, 1972, p. 2. Epistemology became an increasingly important concept in Murray's work after 1970. See, for example, Elwood Murray, "Basis for a Discipline of Communication Epistemology in Interpersonal Communication," Paper presented to a Research Conference on Applied Epistemology in the New Rhetorics, Central States Speech Association, Chicago, Illinois, April 6-8, 1972; Elwood Murray and Joseph L. Stewart, "An Epistemic Based Information-Communication Model for Management of Communication Disorders," Paper presented in "Humanizing the Information Sciences" section, Convention of the International Communication Association, Montreal, Canada, April 25-29,1973; Elwood Murray and Edward A. Lindell, "An Epistemic Based Liberal Arts Curriculum," Paper presented at the Seventh Annual Conference on Value Inquiry, State University of New York at Geneseo, April 27-28, 1973.

4. Murray, "An Epistemic-Based Laboratory in Interpersonal Communication," pp. 2-3.

5. Murray, "An Epistemic-Based Laboratory in Interpersonal Communication," p. 2.

6. Murray, "An Epistemic-Based Laboratory in Interpersonal Communication," p. 3.

7. Murray, "An Epistemic-Based Laboratory in Interpersonal Communication," p. 3.

8. Elwood Murray, "Personality, Communication, and Interpersonal Relations," Southern Speech Journal, XIII (January, 1948), 83.

9. Murray, "An Epistemic-Based Laboratory in Interpersonal Communication," p. 6.

10. Murray's Interdisciplinary Analogue Laboratory, developed during the early 1960's, made even greater use of this idea. Scholars from a variety of disciplines worked together to increase understanding and integrate knowledge.

11. Murray has applied the general systems term "isomorphism" to the general semantic concept of "map territory" as it refers to the transformations between sensory input and language behavior in the human brain and nervous system. 
12. Murray, "An Epistemic-Based Laboratory in Interpersonal Communication," pp. 12-13.

13. Elwood Murray, "Semantic Compatibility in an Interpersonal Communication Laboratory," Paper presented at the Speech Association of America Convention, New York, New York, December 28, 1965, p. 3.

14. Murray, "An Epistemic-Based Laboratory in Interpersonal Communication," p. 9.

15. Murray, "An Epistemic-Based Laboratory in Interpersonal Communication," p. 10.

16. Dr. Myers emphasized that Murray's questions and suggestions always made his students think for themselves.

17. Letter from Dr. Roy Wood, Dean of the School of Speech, Northwestern University, August 15, 1977.

18. Gail E. Myers, "A New Approach-The Laboratory in Interpersonal Communication," Paper presented in honor of Elwood Murray at a National Society for the Study of Communication luncheon, San Francisco, California, March 14, 1964, p. 3.

19. Murray, "Semantic Compatibility in an Interpersonal Communication Laboratory," p. 5.

20. Murray, "Semantic Compatibility," p. 6.

21. Alvin A. Goldberg, "The Effects of a Laboratory Course in General Semantics," Etc.: A Review of General Semantics, XXII, No. 1 (March, 1965), 19-24.

22. Gail Myers and Michele Tolela Myers, The Dynamics of Human Communication: A laboratory Approach (New York: McGraw-Hill, Inc., 1976).

23. McGraw Hill reports that the 1973 edition of The Dynamics of Human Communication sold over 75,000 copies.

24. Examples of such texts include: Gerald Egan, You and Me: The Skills of Communicating to Others (Monterey: Wadsworth Publishing Company, 1977); Lynn Phelps and Sue DeWine, Interpersonal Communication Journal (New York: West Publishing Company, 1976); Kathleen S. Verderber and Rudolph F. Verderber, Inter-Act: Using Interpersonal Communication Skills (California: Wadsworth Publishing Company, 1977); Linda Heum and Richard Heum, Developing Skills for Human Interaction (Ohio: Charles E. Merrill, 1975); Lawrence B. Rosenfeld, Gerald Goldhaber and Val R. Smith, Experiments in Human Communication: A Laboratory Manuel and Workbook (New York: Holt, Rinehart, and Winston, 1975).

25. Increasingly, the focus of Denver's summer programs and conferences turned toward interpersonal relations. In 1946, Murray's workshop in interpersonal relations stressed the application of "new methods of communicating in the various areas wherein interpersonal relations are crucial" (summer school brochure, University of Denver, 1946-47). Specialists from industry, government, and education were invited to discuss the special problems unique to their area and develop curriculum and training programs which would effectively aid individuals in dealing with problems of interpersonal relations. 
26. Examples of recent Interpersonal Communication texts which incorporate material on general semantics are: Kim Giffin and Bobby R. Patton, Fundamentals of Interpersonal Communication (New York: Harper and Row, 1976); William Brooks and Phillip Emmert, Interpersonal Communication (lowa: William C. Brown, 1976); Ron Adler and Neil Towne, Looking Out/Looking In: Interpersonal Communication (New York: Holt, Rinehart and Winston, 1978).

27. Personal letter from Charlotte Read, Institute of General Semantics, October 5, 1977.

28. Tape recorded remarks from Donald Washburn, North Adams State College, September 2, 1977.

29. Personal letter from Charlotte Read, October 5, 1977.

30. Murray, "Communicating and Relating-Undoing the Fragmentations," Eco-Logos, Part III, XXI (2nd quarter, 1975), 18. 